\title{
Role of interleukin 8 on leucocyte-endothelial cell adhesion in intestinal inflammation
}

\author{
H Arndt, M A Bolanowski, D N Granger
}

\begin{abstract}
Background-An important action of interleukin 8 (IL8) is stimulation of granulocytes. The object of this study was to assess the contribution of IL8 to the leucocyte-endothelial cell interactions associated with intestinal inflammation in the rat.

Methods-Two indomethacin injections (48 and 24 hours prior to the experiments) induced a longlasting ileitis in rats. The number of adherent and emigrated leucocytes, leucocyte rolling velocity, and shear rate were monitored in normal and inflamed mesenteric postcapillary venules. Some animals received a monoclonal antibody (MAb) against IL8 or CD11b/CD18 at 24 and 12 hours prior to the experiment.

Results-Indomethacin elicited a sevenfold increase in leucocyte adherence and a 5.4-fold increase in leucocyte emigration, while leucocyte rolling velocity was reduced by nearly $80 \%$. The indomethacin induced increases in leucocyte adherence and emigration were significantly reduced (by $57 \%$ and $67 \%$, respectively) while leucocyte rolling velocity was increased (to $63 \%$ of control) by the IL8-specific MAb. The level of inhibition seen with the IL8 MAb was similar to that associated with administration of a MAb directed against the leucocyte adhesion molecule CD11b/CD18.

Conclusions-IL8 contributes to the leucocyte-endothelial cell interactions elicited in mesenteric venules by indomethacin.

(Gut 1996; 38: 911-915)
\end{abstract}

Keywords: indomethacin, microcirculation, inflammatory bowel disease.

Department of Biophysics, Louisiana

State University -

Medical Center, USA

D N Granger

Department of

Internal Medicine I,

University of

Regensburg, Germany

H Arndt

Molecular and Cellular Biology, The Monsanto Company, St Louis, Missouri, USA

A Bolanowski Correspondence to: Department of Physiology and Biophysics, Louisiana State University - Medica Center, 1501 Kings Highway, Shreveport, Louisiana 71130-3932, USA.

Accepted for publication 29 December 1995 whereas IL10 mRNA is increased in ulcerative olitis but not in Crohn's disease. ${ }^{5}$

Interleukin 8 (IL8) is another cytokine that accumulates in inflamed lesions of patients with activated ulcerative colitis. ${ }^{6}$ Recent findings show that IL8 tissue values and the expression of IL8 gene in biopsy samples from patients with IBD is related to the macroscopic and histological grade of active inflammation. ${ }^{78}$ After appropriate stimulation, IL8 is synthesised mainly by mononuclear phagocytes, however, fibroblasts, epithelial cells, and endothelial cells are all known to produce this powerful cytokine. ${ }^{9-11}$ In intestinal epithelial cell lines, IL 8 synthesis can be stimulated by the inflammatory cytokines ILl and tumour necrosis factor (TNF). ${ }^{12}$ The biological activity of IL8 is very similar to chemotactic peptides like C5a and f-Met-Leu-Phe. ${ }^{13}$ Consequently, a major action of IL8 is activation of neutrophils, ${ }^{14}$ inducing directional migration, increasing the production of reactive oxygen metabolites, and increasing the expression and level of activation of adhesion molecules. ${ }^{15} 16$ There are also reports that suggest that the IL8 secreted by activated endothelial cells inhibits the adhesion of neutrophils to activated endothelial monolayers. ${ }^{17} 18$

Although the published in vitro data suggest that IL8 may exert both pro-inflammatory and anti-inflammatory effects, the limited number of studies that consider IL8 function in vivo suggest that its pro-inflammatory actions dominate. In a rabbit model of lung reperfusion injury a monoclonal antibody against IL8 prevented neutrophil infiltration and tissue injury. ${ }^{19}$ Mulligan and coworkers have recently shown that a murine monoclonal antibody (DM/C7) to human IL8 largely abolishes the inflammatory cell infiltrate and vascular dysfunction observed in a rat model of IgG immune complex induced lung injury. ${ }^{20}$ It was assumed (but not determined) that the IL8 $\mathrm{MAb}$ exerted its beneficial effects by limiting the recruitment of adherent and emigrated neutrophils in the pulmonary microvasculature. With the same monoclonal antibody neutrophil influx in a dermal immune complex induced inflammation in mice could be abolished. ${ }^{21}$ The objects of this study were to determine: (a) whether IL8 contributes to the inflammatory cell infiltrate and mucosal lesion formation observed in a rat model of intestinal inflammation, and (b) whether IL8 mediates the leucocyte-endothelial cell adhesive interactions in postcapillary venules that occurs in the same experimental model.

\section{Methods}

\section{Animal preparation}

Male Sprague-Dawley rats (160-240 g) anaesthetised with $110 \mathrm{mg} / \mathrm{kg}$ Inactin $(\mathrm{Na}-5-$ ethyl-1 (1'-methyl-propyl) 2-thio-barbiturate, Byk Gülden, Konstanz, Germany) were 
catheterised (carotid artery) for continuous measurement and recording of systemic blood pressure and heart rate (Statham P23A Transducer, Oxnard, CA; Grass Recorder, Grass Instruments, Quincy, MA), tracheotomised for facilitating breathing during the experiment, and surgically prepared for microscopic observation of mesenteric venules.

\section{Intravital microscopy}

Animals were placed in a supine position on an adjustable Plexiglas microscope stage and the exteriorised segment of the mid-ileum was draped over an optically clear viewing pedestal permitting transillumination of a $2 \mathrm{~cm}^{2}$ section, as described previously..$^{22} 23$ The exposed bowel wall was draped with saline soaked gauze, the mesentery was covered with Saran wrap (Dow Chemicals, Indiana) to minimise condensation on the objective lens, and continuously superfused with warm bicarbonate buffered salt solution (BBS, $\mathrm{pH} \mathrm{7 \cdot 4)}$ bubbled with $5 \% \mathrm{CO}_{2}-95 \% \mathrm{~N}_{2}$. Animal core temperature was thermostated to $37^{\circ} \mathrm{C}$.

Single unbranched mesenteric venules of 25-35 $\mu \mathrm{m}$ diameter and roughly $150 \mu \mathrm{m}$ in length were transilluminated with a $12 \mathrm{~V}-100 \mathrm{~W}$ light source and observed through an intravital video microscope (Leitz Ortholux II, Germany) with a $\times 40$ objective lens (Zeiss UD 40/0.65, Germany) and a $\times 10$ eyepiece. A video camera (Hitachi WK-C150, Japan) mounted on the microscope projected the image onto a colour monitor (Sony PVM2030, Japan). The images were recorded using a video cassette recorder (Panasonic NV8950, Japan) for playback analysis. Venular diameter $\left(D_{v}\right)$ was measured on or off line using a video image shearing monitor (IPM, LaMesa, CA). Red blood cell centreline velocity ( $\mathrm{Vrbc}$ ) was measured on line with an optical Doppler velocimeter (Microcirculation Research Institute, Texas $A$ and $M$ University). Mean red blood cell velocity was calculated assuming $\mathrm{V}_{\text {mean }}=$ centreline velocity/1 $\cdot 6 .^{24}$ Venular shear rate $(t)$ was calculated based on the Newtonian definition: $\mathrm{t}=8\left(\mathrm{~V}_{\text {mean }} / \mathrm{D}_{\mathrm{v}}\right) \cdot{ }^{25}$

The number of adherent and emigrated leucocytes were determined during playback of videotaped images. A leucocyte was defined as adherent to venular endothelium if it was stationary for at least 30 seconds. Leucocyte adherence was expressed as the number per 100 $\mu \mathrm{m}$ length of the venule. Leucocyte emigration was expressed as the number of white blood cells per microscopic field $\left(1 \cdot 7 \times 10^{-2} \mathrm{~mm}^{2}\right)$. Rolling leucocytes were defined as white blood cells moving at a slower velocity than erythrocytes in the same vessel. The leucocyte rolling velocity $\left(\mathrm{V}_{\mathrm{wbc}}\right)$ was determined from the time a leucocyte required to move along $100 \mu \mathrm{m}$ of the microvessel. A mean of 10 estimates of transit time was used to calculate $\mathrm{V}_{\text {wbc }} \cdot{ }^{23}$

Experimental protocol

Twenty two rats were divided into four groups. Three groups received two subcutaneous injections of indomethacin 48 and 24 hours before the experiment $\left(10 \mathrm{mg} / \mathrm{ml} 5 \% \mathrm{NaHCO}_{3}\right.$, $7.5 \mathrm{mg} / \mathrm{kg}$ each). ${ }^{26}$ One group was treated additionally with a MAb against IL8 (DM/C7, 3 $\mathrm{mg} / \mathrm{kg}$ intravenously) ${ }^{20}$ while another group received a $M A b$ against the leucocyte adhesion glycoprotein CD11b/CD18 (MAb 17, 1.5 $\mathrm{mg} / \mathrm{kg}$ intravenously) ${ }^{27}$ under ether anaesthesia at 24 hours and 12 hours prior to the experiment. DM/C7 was provided by The Monsanto Company (St Louis, Missouri), MAb 17 by Repligen Corporation (Cambridge, Massachusetts). The indomethacin induced changes were not affected by isotype matched non-binding control antibodies $\left(\mathrm{IgG} 1_{\mathrm{K}}\right.$ for IL8, $\operatorname{IgG} 2_{\mathrm{K}}$ for CD11b/CD18, PharMingen, San Diego) and none of the antibodies or its solvent (saline) had an intrinsic effect on the microcirculatory parameters in animals not treated with indomethacin (data not shown). The control group received two subcutaneous injections of the indomethacin vehicle, $5 \% \mathrm{NaHCO}_{3}$.

After all parameters measured on line (arterial pressure, Vrbc, $\mathrm{D}_{\mathrm{v}}$ ) were in a steady state, images from the mesenteric preparations - approximately 10 venules per animal - were videotaped for five minutes.

\section{Tissue analysis}

After intravital microscopy the animals were killed with an overdose of pentobarbital and the intestines were excised and opened longitudinally. Findings were ranked using the following criteria: 0 - no change in serosa or mucosa. 1 - hyperaemic lesions or petechial bleeding, or both, 2 - single mucosal erosion or ulceration, 3 - multiple erosions or ulcerations without any lesions in the serosa and mesentery, or single mucosal erosion or ulcer with hyperemic, adhesive or haemorrhagic lesions in the serosa, 4 -multiple erosions or ulcerations (less than $10 \mathrm{~cm}$ of total length of the intestine involved) with hyperaemic, adhesive or haemorrhagic lesions in the serosa, 5 - multiple erosions or ulcerations (more than $10 \mathrm{~cm}$ of total length of the intestine involved) with hypaeremic, adhesive or haemorrhagic lesions in the serosa. ${ }^{26}$

\section{Myeloperoxidase activity}

Intestinal tissue samples were rapidly excised, rinsed with ice cold saline, blotted dry, and frozen at $-70^{\circ} \mathrm{C}$ until thawing for determination of myeloperoxidase activity using methods previously described. ${ }^{28}$

\section{Statistics}

All data were analysed using standard statistical analysis - that is, analysis of variance with the Scheffe's (posthoc) test. All values are expressed as means (SEM), statistical significance was set at $\mathrm{p}<0 \cdot 05$.

\section{Results}

Figure 1 illustrates the effects of the MAbs against IL8 and CD11b/CD18 on the indomethacin induced increase in leucocyte adherence in rat mesenteric venules compared 


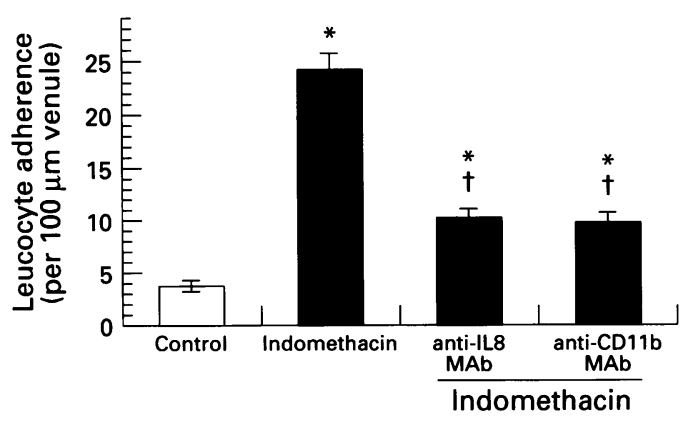

Figure 1 Effect of monoclonal antibodies to IL8 and $C D 11 \mathrm{~b}$ on indomethacin induced leucocyte adherence in rat mesenteric venules. Shown are mean (SEM) values. $\star_{p}<0.05$ relative to control, $t p<0.05$ relative to indomethacin.

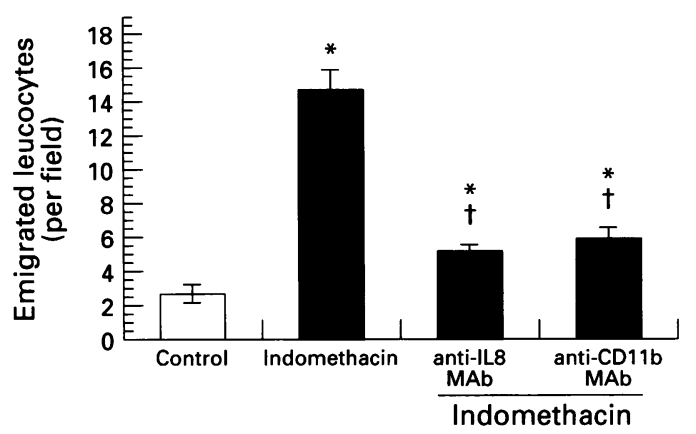

Figure 2 Effect of monoclonal antibodies to IL8 and $C D 11 \mathrm{~b}$ on indomethacin induced leucocyte emigration in rat mesenteric venules. Shown are mean (SEM) values. ${ }^{\star} p<0.05$ relative to control, $+p<0.05$ relative to indomethacin.

with untreated rats. Two subcutaneous injections of indomethacin elicited a nearly sevenfold increase in adherence $(24 \cdot 0(1 \cdot 6) v$ $3.6(0.5)$ leucocytes per $100 \mu \mathrm{m}$ venule in control), which was reduced by $57 \%$ by the antiIL8 MAb $(10.3(0.7)$ and by $60 \%$ by the antiCD1 1b MAb (9.6 (1.0). The 5.4-fold increase in leucocyte emigration (Fig 2) caused by indomethacin injections $(14.5(1.0)$ v $2.7(0.6)$ leucocytes per field in control) was significantly blunted by both monoclonal antibodies (anti- IL8 4.8 (0.5), anti-CD1 1b 5.9 (0.7)).

The Table presents the data for leucocyte rolling velocity, venular wall shear rate, macroscopic mucosal ulcerations, and myeloperoxidase activity. The reduction of leucocyte rolling velocity by $76 \%$ by indomethacin treatment was partly prevented by anti-IL 8 and anti-CD $11 \mathrm{~b}$ $\mathrm{MAb}(63 \%$ and $67 \%$ reduction $v$ control, respectively). The venular wall shear rate was not affected by indomethacin, indomethacin/ anti-IL8, or indomethacin/anti-CD11b treatment and therefore not the cause for changed rolling and emigration.

Effects of indomethacin (INDO) and the monoclonal antibodies against IL8 and $C D 11 b / C D 18$ on leucocyte rolling velocity ( $V w b c)$, venular wall shear rate $(S R)$, mucosal ulceration, and myeloperoxidase activity (MPO) as a parameter of granulocyte tissue infiltration

\begin{tabular}{|c|c|c|c|c|}
\hline & $\begin{array}{l}V w b c \\
(\mathrm{~mm} / \mathrm{s})\end{array}$ & $\begin{array}{l}S R \\
\left(s^{-1}\right)\end{array}$ & $\begin{array}{l}\text { Mucosal } \\
\text { ulceration }\end{array}$ & $\begin{array}{l}M P O \\
(U / g w w)\end{array}$ \\
\hline $\begin{array}{l}\text { Control }(n=6) \\
\text { INDO }(n=5) \\
\text { INDO+ anti-IL8 MAb }(n=6) \\
\text { INDO + anti-CD1 1b MAb }(n=5)\end{array}$ & $\begin{array}{l}73 \cdot 2(6 \cdot 4) \\
17 \cdot 0(1 \cdot 3)^{\star} \\
27 \cdot 2(4 \cdot 5)^{\star} \dagger \\
24 \cdot 8(2 \cdot 1)^{\star} \dagger\end{array}$ & $\begin{array}{l}432(28) \\
420(38) \\
441(35) \\
443(29)\end{array}$ & $\begin{array}{l}0 \\
4 \cdot 0(0 \cdot 5)^{\star} \\
3 \cdot 6(0 \cdot 6)^{\star} \\
3 \cdot 4(0 \cdot 5)^{\star}\end{array}$ & $\begin{array}{l}46 \cdot 0(14 \cdot 0) \\
89 \cdot 1(13 \cdot 0)^{\star} \\
35 \cdot 9(18 \cdot 9) \dagger \\
45 \cdot 9(4 \cdot 7) \dagger\end{array}$ \\
\hline
\end{tabular}

Shown are mean $\left(\right.$ SEM) values. ${ }^{\star}$ Denotes $p<0.05$ relative to control, tshows $p<0.05$ relative to INDO ( $n=$ number of animals per group).
The indomethacin induced increase of leucocyte adhesion in mesenteric venules was accompanied by macroscopic mucosal ulcerations of the small bowel (ulcer index $4.0(0 \cdot 5)$ $v 0$ in control) and an increase of myeloperoxidase $(89.11(13.0) \mathrm{U} / \mathrm{g}$ wet weight $v 46.0$ $(14 \cdot 0)$ in control), an index of granulocyte infiltration into the inflamed tissue. While the macroscopic extent of ulceration was not significantly reduced by treatment with either MAb, both the IL8 and CD11b MAbs did blunt the indomethacin induced in Myeloperoxidase activity (Table).

\section{Discussion}

The accumulation of leucocytes in inflamed tissue is preceded by leucocyte adhesion to vascular endothelium. This rate limiting step in the inflammatory response is modulated by a variety of adhesion glycoproteins expressed on the surface of leucocytes and endothelial cells. Several cytokines affect the expression or state of activation of these cell adhesion molecules. For granulocyte-endothelial cell interactions, the synthesis of E- and P-selectin has been shown to be inducible by IL1 and TNF. ${ }^{29-31}$ Granulocyte-macrophage colony stimulating factor and TNF $\alpha$ induce neutrophils and monocytes to shed L-selectin and simultaneously mobilise intracellular pools of the CD11b/CD18 to the leucocyte surface, ${ }^{32} 33$ thereby promoting attachment of neutrophils to endothelium.

The role of IL8 in modulating leucocyteendothelial interactions is presently controversial. The IL8 produced by cytokine activated endothelial cells and by neutrophils in itself ${ }^{1834}$ has been shown to stimulate the binding activity of CD11b/CD18 on the surface of neutrophils. ${ }^{15}$ Smith and coworkers have also shown that there is an IL8 dependent mechanism of neutrophil transmigration through cytokine activated endothelium, which is CD11b/CD18 dependent. ${ }^{35}$ This pro-inflammatory action of IL8 was recently shown in a rat model of IgG immune complex induced lung inflammation and vascular injury. ${ }^{20}$ Mulligan and coworkers showed a considerable reduction in the tissue influx of neutrophils and the vascular injury induced by IgG immune complexes in rats receiving the anti-human IL8 MAb DM/C7. On the other hand, there are reports that invoke an antiinflammatory role of IL8. It has been shown that IL8 inhibits the adhesion of neutrophils to activated endothelial cells in vitro ${ }^{17} 18$ and reduces neutrophil accumulation in acutely inflamed tissues. ${ }^{36}$

Although IL8 has been implicated in the pathobiology of intestinal inflammation, no attempts have been made to directly assess the role of this cytokine in an experimental model of gut inflammation. We have previously shown that the indomethacin model of intestinal inflammation in the rat developed by Yamada and coworkers ${ }^{26}$ is characterised by an intense recruitment of adherent and emigrated leucocytes in mesenteric venules, granulocyte accumulation in mucosal tissue, 
and the development of mucosal ulcers. ${ }^{37}$ The results of this study clearly suggest a role for IL8 in the recruitment of leucocytes elicited by indomethacin. The antihuman IL8 MAb DM/C7 profoundly attenuated the accumulation of adherent and emigrated leucocytes in postcapillary rat venules and the increased mucosal myeloperoxidase activity normally seen after indomethacin treatment. These findings are consistent with the beneficial effects of the same IL8 MAb (DM/C7) in a rat model of IgG immune complex induced lung inflammation and in a dermal immune complex induced inflammation in mice. ${ }^{2021}$

Inasmuch as the anti-IL8 MAb was as effective as a $M A b$ against $C D 11 \mathrm{~b} / \mathrm{CD} 18$ in reducing the recruitment of adherent and emigrated leucocytes in the same model of chronic intestinal inflammation, it seems likely that IL8 promotes the leucocyte-endothelial cell interactions by either increasing the surface expression or activation of CD11b/CD18 on leucocytes. This $\beta_{2}$-integrin is the main ligand for high affinity binding of leucocytes to and transmigration through vascular endothelium. ${ }^{38}$ However, we cannot exclude the possibility that IL8 may promote leucocyteendothelial cell adhesion, at least partly by increasing the surface expression of endothelial cell adhesion molecules. There is evidence that IL8 can bind to the surface of endothelial cells, where it can act as an activator and chemoattractant of neutrophils. ${ }^{39}$

In IgG immune complex induced lung inflammation in rats, IL8 MAb treatment effectively attenuated both the recruitment of inflammatory cells and the increased microvascular permeability to albumin. ${ }^{20}$ However, in this study we observed that while the IL8 $\mathrm{MAb}$ reduced the accumulation of granulocytes normally observed in indomethacin induced intestinal inflammation, it did not blunt the accompanying mucosal ulceration response. The finding that the reduced mucosal accumulation of granulocytes was not accompanied by protection against indomethacin induced intestinal mucosal ulcerations is consistent with the results of Yamada et $a l,{ }^{26}$ indicating that in this model of inflammation granulocyte infiltration into the mucosa is a consequence rather than a cause of the intestinal lesions. In this regard, it should be noted that treatment with $\mathrm{DM} / \mathrm{C} 7$ offers no protection in a neutrophil independent model of IgA immune complex induced model of lung vascular injury. ${ }^{20}$ Another explanation for the ineffectiveness of the anti-IL8 MAb could be the involvement of macrophages at the examined stage (50-54 hours after the first indomethacin administration) of the cascade of intestinal inflam-mation. ${ }^{40}$ While the IL8 MAb did not prevent or reduce indomethacin induced mucosal ulceration, it may have afforded some protection against the microvascular injury that is likely to accompany the ulceration response.

1 Sartor RB. Cytokines in intestinal inflammation: pathophysiological and clinical considerations. Gastroenterology 1994; 106 533-9.
2 Isaacs $\mathrm{KL}$, Sartor RB, Haskill JS. Cytokine mRNA in inflammatory bowel disease mucosa detected by PCR amplification. Gastroenterology 1992; 103: 1587-95.

3 Mullin GE, Lazenby AJ, Harris ML, Bayless TM, James SP. Increased interleukin-2 messenger RNA in the intestinal mucosal lesions of Crohn's disease but not ulcerative colmucosal lesions of Crohn's disease but not
itis. Gastroenterology 1992; 102: 1620-7.

4 Breese E, Braegger CP, Corrigan CJ, Walker-Smith JA, MacDonald TT. Interleukin-2- and interferon-secreting $T$ cells in normal and diseased human intestinal ing $\mathrm{T}$ cells in normal and diseased

5 Mullin GE, Vezza FR, Sampat A, Maycon Z, Kalz R, Eisenstein, et al. Abnormal IL-10 mRNA production in the intestinal mucosal lesions of inflammatory bowel disease. Gastroenterology 1993; 104: A751.

6 Mahida YR, Ceska M, Effenberger F, Kanlak L, Lindley I, Hawkey CJ. Enhanced synthesis of neutrophil-activating peptide-1/interleukin-8 in active ulcerative colitis. Clin $S_{c i}$ 1992; 82: 273-5.

7 Mitsuyama K, Toyonaga A, Sasaki E, Watanabe K, Tateishi $\mathrm{H}$, Nishiyama $\mathrm{T}$ et al. IL-8 as an important chemoattracH, Nishiyama T et al. IL-8 as an important chemoattractant for neutrophils in ulcerative colitis

8 Mazzzucchelli L, Hauser C, Zgraggen K, Wagner H, Hess $M$, Laissue JA, et al. Expression of interleukin-8 gene in inflammatory bowel disease is related to the histological grade of active inflammation. Am $\mathcal{F}$ Pathol 1994; 144: 997-1007.

9 Peveri P, Waltz A, Dewald B, Baggioloini M. A novel neutrophil-activating factor produced by human mononuclear phagocytes. $\mathcal{F}$ Exp Med 1988; 167: 1547-59.

10 Strieter RM, Phan SH, Showell HJ, Remick DG, Lynch JP, Genord M, et al. Monokine-induced neutrophil chemotactic factor gene expression in human fibroblasts. $\mathcal{F}$ Biol tactic factor gene expression

11 Schroeder JM, Christophers E. Secretion of a novel and homologous neutrophil-activating peptides by LPS-stimulated human endothelial cells. $\mathcal{F}$ Immunol 1989; 142: 244-51.

12 Eckmann L, Jung HC, Schürer-Maly C, Panja A, Morzycka-Wroblewska E, Kagnoff MF. Differential cytokine expression by human intestinal epithelial cell lines: regulated expression of interleukin 8 . Gastroenterology 1993; 105: 1689-97.

13 Thelen M, Peveri P, Kernen P, Tscharner V, Walz A, Baggiolini $M$. Mechanism of neutrophil activation by $\mathrm{NAF}$, a novel monocyte-derived peptide agonist. FASEB f 1988; 2: 2702-6.

14 Baggiolini M, Walz A, Kunkel SL. Neutrophil-activating peptide-1/interleukin-8, a novel cytokine that activates peptide-1/interleukin-8, a novel cytokine that

15 Detmers PA, Lo SK, Olson-Egbert E, Walz A, Baggiolini $M$, Cohn ZA. Neutrophil-activating protein-1/interleukin-8 stimulates the binding activity of the leukocyte adhesion receptor $C D 11 \mathrm{~b} / \mathrm{CD} 18$ on human neutrophils. $\mathcal{f}$ Exp Med 1990; 171: 1155-62.

16 Baggiolini M, Imboden P, Detmers P. Neutrophil activation and the effects of interleukin-8/neutrophil-activating peptide-1 (IL-8/NAP-1). In: Baggiolini M, Sorg C, eds. Vo 4. Cytokines 1992; Basel: Karger, 1-17.

17 Wheeler ME, Luscinskas FW, Bevilacqua MP, Gimbrone Jr MA. Cultured human endothelial cells stimulated with MA. Cultured human endothelial cells stimulated with cytokines or endotoxin produce an inhibitor

18 Gimbrone Jr MA, Obin MS, Brock AF, Luis EA, Hass PE Hébert CA, et al. Endothelial interleukin-8: a novel inhibitor of leukocyte-endothelial interactions. Science 1989; 246: 1601-3

19 Sekido N, Mukaida N, Harada A, Nakanishi I, Watanabe Y, Matsushima K. Prevention of lung reperfusion injury in rabbits by a monoclonal antibody against interleukin-8. Nature 1993; 365: 654-7.

20 Mulligan MS, Iones ML, Bolanowski MA, Baganoff MP, Deppeler CL, Meyer DM, et al. Inhibition of lung inflammatory reactions in rats by an anti-human IL- 8 antibody. m Immunol 1993; 150: 5585-95.

21 Zhang Y, Ramos BF, Baganoff MP, Deppeler CL, Meyer DM, Widomski DL, et al. The role of IL-8 and mast cellgenerated TNF $\alpha$ in neutrophil recruitment. Inflammation 1995; 19: 132 .

22 Granger DN, Benoit JN, Suzuki $M$, Grisham MB. Leukocyte adherence to venular endothelium during ischemia/reperfusion. Am $\mathcal{F}$ Physiol 1989; 257: G683-8.

23 Arndt H, Smith CW, Granger DN. Leukocyte-endothelia cell adhesion in spontaneously hypertensive and normotensive rats. Hypertension 1993; 21: 667-73.

24 Davis MJ. Determination of volumetric flow in capillary tubes using an optical Doppler velocimeter. Microvasc Res 1987; 34: 223-30.

25 House SD, Lipowsky H. Leukocyte-endothelium adhesion: microhemodynamics in mesentery of the cat. Microvasc Res 1987; 34: 363-79.

26 Yamada T, Deitch E, Specian RD, Perry MA, Sartor RB Grisham MB. Mechanisms of acute and chronic intestinal Grisham MB. Mechanisms of acute and chronic intestinal inflammation induce 17 : 641-62.

27 Freyer DR, Morganroth ML, Todd RF. Surface Mol (CD11b/CD18) glycoprotein is upmodulated by neutrophils recruited to sites of inflammation in vivo. Inflammation 1989; 13: 495-505.

28 Grisham MB, Benoit JN, Granger DN. Assessment of leukocyte involvement during ischemia and reperfusion of intestine. Methods Enzymol 1990; 186: 729-42.

29 Bevilacqua MP, Pober JS, Mendrick DL, Cotran RS Gimbrone Jr MA. Identification of an inducible 
endothelial-leukocyte adhesion molecule. Proc Natl Acad Sci USA 1987; 84: 9238-42.

30 Weller A, Isenmann S, Vestweber D. Cloning of the mouse endothelial selectins. Expression of both $\mathrm{E}$ - and P-selectin is inducible by tumor necrosis factor. $\mathrm{f} \mathrm{Biol} \mathrm{Chem} \mathrm{1992;}$ 267: 15176-83.

31 Sanders WE, Wilson RW, Ballantyne CM, Beaudet AL. Molecular cloning and analysis of in vivo expression of
murine P-selectin. Blood 1992; 80: 796-800.

32 Arnaout MA, Wang EA, Clak SC, Sieff CA. Human recombinant granulocyte-macrophage colony-stimulating factor increases cell-to-cell adhesion and surface expression of adhesion-promoting surface glycoproteins on mature granulocytes. F Clin Invest 1986; 78: 597-601.

33 Griffin JD, Spertini O, Ernst TJ, Belvin MP, Levine HB, Kanakura Y, et al. Granulocyte-macrophage colony-stimulating factor and other cytokines regulate surface expression of the leukocyte adhesion molecule-1 on human neutrophils, monocytes, and their precursors. 7 Immunol 1990; 145: 576-84.

34 Hébert CA, Luscinskas FW, Kiely J-M, Luis EA, Darbonne WC, Benett GL, et al. Endothelial and leukocyte forms of IL-8: conversion by thrombin and interactions with neutrophils. F Immunol 1990; 145: 3033-40.
35 Smith WB, Gamble JR, Clark-Lewis I, Vadas MA. Chemotactic desensitization of neutrophils demonstrates interleukin-8 (IL-8)-dependent and IL-8independent mechanisms of transmigration through cytokine-activated endothelium. Immunology 1993; 78: 491-7.

36 Hechtman DH, Cybulski MI, Fuchs HJ, Baker JB, Gimbrone Jr MA. Inhibitor of polymorphonuclear leukoGimbrone Jr MA. Inhibitor of polymorphonuclear leuko-
cyte accumulation at sites of acute inflammation. $\mathcal{F}$

37 Arndt H, Palitzsch K-D, Grisham MB, Granger DN. Metronidazole inhibits leukocyte-endothelial cell adhesion in rat mesenteric venules. Gastroenterology 1994; 106: 1271-6.

38 Furie MB, Tancino MCA, Smith CW. Monoclonal antibodies to leukocyte integrins $\mathrm{CD} 11 \mathrm{a} / \mathrm{CD} 18$ and $\mathrm{CD} 1 \mathrm{~b} /$ CD18 or intercellular adhesion molecule- 1 inhibit chemoattractant-stimulated neutrophil transendothelial migration in vitro. Blood 1991; 78: 2089-97.

40 Nygard G, Anthony A, Piasecki C, Trevethick MA, Hudson M, Dhillon AP, et al. Acute indomethacininduced jejunal injury in the rat: early morphological induced jejunal injury in the rat: early morphological 567-75. 